\title{
Functioning of ASHAs under National Health Mission in Punjab: An Appraisal
}

\author{
Pawan Kumar Sharma and Poonam Sandhir* \\ Centre for Research in Rural and Industrial Development (CRRID), Chandigarh-160019, India \\ "E-mail: poonam19s@yahoo.in
}

\section{ARTICLE INFORMATION}

Received: August 16, 2018

Revised: September 05, 2018

Accepted: September 22, 2018

Published online: October 08, 2018

Keywords:

ASHA, National Health Mission, NHM, public health

DOI: https://doi.org/10.15415/jmrh.2018.51003

\begin{abstract}
The present paper ascertains the functional efficacy of ASHAs and suggests measures for the optimization of their functioning in Punjab. For carrying out the study, different phases included random selection of three districts followed by two health blocks from each district and three sub centres from each block and subsequently one village from each sub centre. List of eligible women who had delivered a baby during the last three months prior to the survey was prepared and at last stage, five women from each village were selected at random. The findings revealed that the norms, including the age limit, educational qualification, residence and marital status set for the selection of ASHAs revealed clear adherence of the NHM guidelines. However two-thirds of the ASHAs were covering a population of more than 1,000 persons. About 90 per cent of the ASHAs couldn't specify their job responsibilities promptly on the activities related to spreading health awareness among adolescents, promoting hygiene practices, generating awareness on preventive measures on RTI/STI, HIV/AIDS, tobacco and alcoholism. About 94 per cent of ASHA workers had received drug kit. However there were delays in the replenishment of drugs. As per NHM guidelines, no drug kit has AYUSH medications in it. Inter-sectoral collaboration among the ASHAs, ANMs, PRI members and AWWs was more or less satisfactory even though ASHAs intervention in VHSNC meeting was not encouraging due to non-cooperation of other stakeholders. For strengthening of the ASHA programme, it is essential that the factors discouraging them are addressed properly.
\end{abstract}

\section{Introduction}

Notwithstanding significant augmentations achieved in the health sector during the past decades, the public health challenges have become not only so huge, but are also growing and shifting at an unprecedented rate in the country. For meeting the health challenges, the country has created, expanded and strengthened a vast public health infrastructure base, including sub-centres, primary health centres and community health centres since Independence (NIHFW, SIHFW\& UNFPA, 2007-08). These health facilities are largely manned by auxiliary nurse midwives, male health workers and lady health visitors. Yet, the large majority of the population remained uncovered by these institutions and paramedical staff even for health concerns which are preventable and easily treatable. A need to revitalize the crumbling public health system was felt in due course of time. Taking cues from past experiences, the National Rural Health Mission (renamed as NHM) was launched by the Government of India in 2005.

One of the core strategies of the reforms under NHM was the initiation of the band of female volunteers residing in villages/hamlets appropriately named "Accredited Social Health Activist" (ASHA), a central feature under enhancing community participation. These ASHAs were to play a central role in NRHM (CORT, 2007). The framework of the NRHM underlined one ASHA for every village having a population of at least 1,000 persons. They were assigned the task of providing effective services on the parameters including primary medical care, mobilization of the community so that utilization of the existing health infrastructure increased, among others.

ASHAs efficacy was dependant on several factors - her own cognitive competency (including capacity building), aptitude, and attitude, effective relationship with other key health functionaries like Anganwadi workers, auxiliary nurse midwives, PHC staff etc., the dynamics between the ASHAs and PRIs including selection, interface, coordination, and supervision, and acceptance of the ASHAs by the community (NIHFW, NIAHR \& UNFPA, 2007-08).

On the whole, ASHAs were visualized to be the first contact for health related activities by the disadvantaged sections of the population especially women and children. Her functional efficacy at the grass root level is critical in 
achieving goals under NHM. To hasten execution of the ASHA programme suitable and well-timed research inputs are required for mid-course Programme corrections so as to achieve the desirable goals. There is no such systematic study available for the state of Punjab to ascertain the functional efficacy of the ASHA Programme. The present study fills this gap.

\section{Objectives}

The study aimed to examine ground implementation status of the ASHA programme under NHM and to identify the factors affecting the implementation of ASHA programme in Punjab. The specific objectives of this evaluative study are to find out implementation of ASHA programme guidelines as laid in NHM as regards their recruitment; to ascertain the training process in terms of its adequacy and gaps in knowledge retention experienced by them while discharging their duties; to assess the knowledge of ASHA workers about their roles and responsibilities; to understand the appropriateness and timeliness of payment of incentives and compensation money on performance based incentives to be paid to ASHAs; to know views of different stakeholders and their satisfaction level regarding different aspects of ASHAs including their social acceptance and community support and activities which ASHAs are unable to perform; and to make suggestions to improve the functional efficacy of the ASHA Programme in the state.

\section{Methodology}

The present cross-sectional study was conducted in Punjab on the behest of the Ministry of Health and Family Welfare, Government of India. The state has 22 districts divided into three cultural regions namely Doaba, Majha and Malwa regions. For carrying out the study multistage random sampling technique was used. It gives an equal chance of being selected to every member of the population. In first phase, one district was selected at random from each of the three cultural regions in Punjab. The three districts selected at random were Shaheed Bhagat Singh Nagar (SBS Nagar) from the Doaba Region, Tarn Taran district of the Majha region and Fatehgarh Sahib district of the Malwa Region. The districts were selected so as to make these representative for the state of Punjab.

Every district is divided into a number of health blocks depending upon area and population to be served. In next stage, two health blocks were selected at random from each of the three selected districts. This was followed by the selection of sub-centres. Three sub-centres from each of the sampled health blocks were selected at random. Subsequently, one village from each of the sub-centre was selected at random.
List of eligible women from each of these villages who had delivered a baby during the last three months prior to the survey was prepared with the help of ASHA and ANMs. At last stage, five women from each village were selected at random. Finally, the study participants included one ASHA worker, one ANM, one AWW, one PRI member and five eligible women from every village. The study tools included five types of different pre-designed and pre-tested questionnaires - one each meant for ASHA worker, ANM, AWW, PRI member and eligible women. All these tools were as per the standards laid under the IPHS which are considered as the benchmarks for quality expected from various components of public health care planning including the ASHA programme across the country as well in the state of Punjab. In all, the sample for the study constituted 18 ASHA workers, 18 ANMs, 18 AWWs, 18 PRI members and 90 eligible women from 18 villages.

The data were then analyzed with the help of SPSS20 and Microsoft Excel-2007. Appropriate tables have been used for presentation of results. The survey was conducted after obtaining permission from the NHM, Government of Punjab.

The strength of the study was that the authors of the study conducted the survey by themselves. This ensured the reliability and comparability of data. The pioneer study can be treated as the baseline study for assessing the functional efficacy of the Programme. The study is intended not merely as evaluative in nature to assess what has been accomplished, but also recommendatory in character by way of suggesting mid-course corrections in the implementation of the ASHA Programme in Punjab. The study has made implementable recommendations based on the findings of the study.

\section{Results and Discussions}

\subsection{Accredited Social Health Activists (ASHAs)}

The norms laid in the ASHA Programme includes that the place of work and residence of ASHAs must be same and also should not be unmarried. There was no hard and fast rule laid in the programme as regards ASHAs age and literacy status but those in the age of 25 to 45 years having attained the education level of matric to be given preference. A relaxation on these parameters was allowed in case no suitable female with due qualification was found available in the village community.

Table 1 illustrates that 17 of the total 18 ASHA workers (94.4 per cent) were in the prescribed age group of 25 to 45 years. The minimum age of the ASHA workers was 30 years and maximum age 47 years. Except one all other 17 ASHAs (94.4 per cent) had attained an educational level up to the higher secondary level. There was only one ASHA 
Table 1: Work Profile of ASHAs $(\mathrm{N}=18)$

\begin{tabular}{|c|c|}
\hline Characteristics & $\begin{array}{l}\text { Number of ASHAs } \\
\text { (in per cent) }\end{array}$ \\
\hline \multicolumn{2}{|l|}{ Age (in years) } \\
\hline Below 35 & $10(55.6)$ \\
\hline $36-40$ & $4(22.2)$ \\
\hline $41-45$ & $3(16.7)$ \\
\hline Above 45 & $1(5.6)$ \\
\hline \multicolumn{2}{|l|}{ Education qualification } \\
\hline Primary & $1(5.6)$ \\
\hline Secondary & $8(44.4)$ \\
\hline Higher secondary & $8(44.4)$ \\
\hline Graduate and above & $1(5.6)$ \\
\hline \multicolumn{2}{|l|}{ Marital status } \\
\hline Married & $16(88.9)$ \\
\hline Widow & $2(11.1)$ \\
\hline \multicolumn{2}{|l|}{ Type of family } \\
\hline Nuclear & $10(55.6)$ \\
\hline Joint & $8(44.4)$ \\
\hline Average size of the family & 5 \\
\hline \multicolumn{2}{|l|}{ Economic status } \\
\hline $\mathrm{BPL}$ & $6(33.3)$ \\
\hline Non-BPL & $12(66.7)$ \\
\hline Work and resident place of ASHA is same & $18(100.0)$ \\
\hline \multicolumn{2}{|l|}{ Stay in this village (in years) } \\
\hline Up to 10 years & $3(16.7)$ \\
\hline $11-20$ years & $8(44.4)$ \\
\hline $21-30$ years & $6(33.3)$ \\
\hline $31-40$ years & $1(5.6)$ \\
\hline
\end{tabular}

whose education attainment was outside the prescribed standards. As visualized in the NHM, no unmarried female was appointed as ASHA worker; about 90 per cent of them were married and the rest were widows. A study conducted in Uttar Pradesh gave that 1.7 per cent of the ASHAs were unmarried females (NIHFW, SIHFW and UNFPA, 200708). A study carried out in Orissa showed that like Punjab no unmarried female was appointed as ASHA worker (NIHFW, NIAHRD and UNFPA, 2007-08).

The economic status of all the ASHA workers was observed to be quite poor. In fact, one-third of them belonged to the Below Poverty Line (BPL) category. As envisaged in the NHM, all the 18 ASHA workers were primarily usual residents of the village. More than 80 per cent of the ASHA workers, that is, 15 of the 18 ASHAs, were residing in the village for more than a decade. The work place and residence being same has made their $24 \times 7$ availability to the community they are serving. On the whole, the norms, including the age limit, educational qualification, residence and marital status set for the selection of ASHAs revealed clear adherence of the NHM guidelines in the state of Punjab.

\subsection{Selection of ASHAS}

Three out of every four ASHA workers reported that the Gram Sabha has played a decisive role in their selection. Fourteen of the 18 ASHAs further stated that they were the only candidate who had shown their interest in the post of the ASHA worker. Two-thirds of the ASHAs stated that the village ANM was the primary source from where they came to know about the requirement of ASHA workers in their respective villages. Village panchayat, relatives, announcement in the village, a medical officer (MO), LHV and AWW were the other sources disseminating information on the commencement of the ASHA worker programme in the village. The views of ANMs, PRI members and ASHA workers substantiate that the NHM guideline were adhered to a great extent as regards the selection criteria and selection process of ASHAs.

\subsection{Work profile}

One ASHA for every village with a population of 1,000 persons was recommended in NRHM so that they could undertake activities assigned to them effectively. Table 2 displays a huge gap in this regard as 12 of the 18 ASHAs (66.7 per cent) covered a population of more than 1,000 persons. A study of Mysore district highlighted that 56.5 per cent of ASHAs served a population of 800 to 1200 and others catered to more population (Nagaraj, S. et al., 2017).

On an average an ASHA worker was spending three hours per day on performing the duties assigned to her. There was no such criterion fixed by ASHA workers themselves for undertaking the household visits. The household visits were need based. They were visiting households as per their requirement.

A cross-sectional study of Mysore district gave that 25 per cent of ASHAs worked for less than 12 hours in a week and 46.3 per cent of ASHAs worked for 12 to 20 hours (Nagaraj, S. et al., 2017).

Issuance of identity cards (ID) by the appropriate authorities is imperative to give a feeling to the ASHAs that they are part of the formal health system in the state. Thirteen of the 18 ASHAs (72.2 per cent) stated that they have identity cards issued by the health department. Three out of every four ASHA workers found these identity cards 
Table 2: Work Profile of ASHAs $(\mathrm{N}=18)$

\begin{tabular}{|c|c|}
\hline Characteristics & $\begin{array}{l}\text { Number of } \\
\text { ASHAs } \\
\text { (in per cent) }\end{array}$ \\
\hline \multicolumn{2}{|l|}{ Size of population served by ASHA } \\
\hline Less than 1000 & $6(33.3)$ \\
\hline 1001 to 1500 & $8(44.4)$ \\
\hline 1501 to 2000 & $2(11.1)$ \\
\hline More than 2000 & $2(11.1)$ \\
\hline $\begin{array}{l}\text { Average hours spend per day to perform } \\
\text { duties }\end{array}$ & 3 \\
\hline $\begin{array}{l}\text { Frequency of household visits as per the } \\
\text { requirement }\end{array}$ & $18(100.0)$ \\
\hline \multicolumn{2}{|l|}{$\begin{array}{l}\text { Themes for generating awareness in the } \\
\text { past three months in the village }\end{array}$} \\
\hline Nutrition & $12(66.7)$ \\
\hline Maternal health & $11(61.1)$ \\
\hline Newborn care & $10(55.6)$ \\
\hline Health & $9(50.0)$ \\
\hline Family planning & $8(44.4)$ \\
\hline Adolescent health & $5(27.8)$ \\
\hline Sanitation & $3(16.7)$ \\
\hline $\begin{array}{l}\text { Percentage of home deliveries attended } \\
\text { by ASHAs }\end{array}$ & $0(0.0)$ \\
\hline $\begin{array}{l}\text { Received ID card from state health } \\
\text { authorities }\end{array}$ & $13(72.2)$ \\
\hline
\end{tabular}

useful. This ID card helped them in ensuring that the treatment to patients is given on priority basis.

\section{Training}

The ASHA programme guidelines highlight the importance of induction training as well as orientation trainings (Sangeeta Kori et. al., 2015). All ASHAs had received induction training. The situation was better as compared to other states as a study conducted in Uttar Pradesh showed that 10 per cent of the ASHAs were still to receive training (NIHFW, SIHFW and UNFPA, 2007-08). On the issue of quality of training received by them, two-thirds of the ASHAs opined that the induction training sessions were quite overcrowded.

The distance between the village where ASHAs were residing and the place where induction training was imparted was not too long. Almost 90 per cent of the ASHAs did not have to travel a distance beyond 20 kilometers. All ASHAs rated the induction training to be adequate on the themes such as antenatal, natal and postnatal care, child health, newborn care, nutrition, and commonly used medicines. On themes including water, sanitation and personal hygiene and human biology training was rated inadequate. Interestingly, one-third of the ASHAs found too much emphasis on human biology.

\section{Motivational Factors}

Economic incentive associated with the functions to be performed by ASHA workers was reported to be the prime factor motivating them to apply for this job. About 72 per cent of them wanted to earn money by working as an ASHA worker. The next important motivating factor as expressed by 17 per cent of the ASHA workers was their aspiration to be absorbed in the government sector in one or the other capacity. In addition to the ambition of getting a government job in due course of time the other factor was increase in their social reputation. More than 80 per cent (15 of the total of 18) of the ASHAs aspired to be an ANM later on in their carrier. The philosophy of ASHA as a volunteer was subscribed by only one ASHA worker. The expected philosophy of ASHA as a volunteer was not reported to be the critical factor to join as an ASHA worker.

A rapid appraisal of ASHAs carried out in Orissa gave that most motivating factor for ASHAs were to earn more money (71 per cent) and serve the community (33.8 per cent) (NIHFW, NIAHRD and UNFPA, 2007-08).

\subsection{Current Roles and Responsibilities}

It was found that not all ASHAs interviewed were aware about all the responsibilities assigned to them. It was found that ASHAs have comprehended the activities on providing counseling to mothers on safe delivery, newborn care and immunization to a great extent. However, about 90 per cent of the ASHAs couldn't specify their job responsibilities promptly on the activities related to spreading health awareness among adolescents, promoting hygiene practices especially those related to hand washing, generating awareness on preventive measures on RTI/STI and HIV/ AIDS, and generating awareness on prevention of tobacco and alcoholism.

The activities which ASHA are able to perform effectively include registration of pregnant women, provide counselling on antenatal and post natal care and safe delivery, accompanying the pregnant women to the hospital, help ANM for immunization, motivate couples on family planning practice, distribution of iron and folic acid (IFA), oral pills and oral rehydration solution (ORS) and inform AWW/ANM on births and deaths. Apart from accompanying women patients to higher health care centres 
and attending them in those health centres during the odd hours of the day, lack of the capacity and skills of the ASHA workers to carry out a number of other activities effectively was quite much evident.

A similar study conducted in Wardha district of Maharashtra revealed that most of the ASHAs engaged themselves in ANC, PNC, escorting pregnant women for checkup and delivery, newborn care and referral, identify danger signs of pregnancy and child illnesses and health education during home visits. However their role in promoting breastfeeding, complementary feeding, contraceptives use and building household toilets was not much evident (Guha, I. et al. 2018).

\subsection{Coordination}

Micro-planning has been a major thrust area under the NHM for improving the health and nutritional status of women and children in the community they are serving. As per the NHM guidelines, The ASHA programme suggested that for developing an inclusive village health plan, the ASHAs were to be associated with the Village Health, Sanitation and Nutrition Committee (VHSNC) of the gram panchayat. The mandate was to have at least one meeting every month. All members are to participate in every meeting for making the meeting a success. However, it was found on the ground that VHSNC meeting are not held every month as envisaged under NHM. It was observed during the field survey that the incentive meant for ASHAs for organizing VHSNC meeting was the prime reason motivating them to organize these meetings even when only a few members are present. This forum was primarily used by ASHAs to plan for killing of malaria parasite. On this aspect micro-planning was somewhat visible.

The ASHAs also raised their voice against the deceitful practices followed by PRI members while utilizing the money earmarked to VHSNCs. In some cases, entire money was consumed by them for the purposes best known to them. The ANMs and ASHAs were directed by them to arrange suitable bills as a cover up to prove that the money was utilized for the earmarked tasks. The ASHAs were of the view that this malpractice by the PRI members was damaging their own image as they are involved in arranging fake bills. This has created their wrong image that they are not only involved in corrupt practices in the matters related to VHSNC but even in performing routine matters of the sub-centres. A few of the ASHAs even recommended the survey team to recommend the government to withdraw this money sanctioned to VHSNCs. They felt that this would save them from the humiliation involved in arranging fake bills. ASHAs need to be motivated to prepare a comprehensive health plan with a full proof system checking any corrupt practices.

\section{Drugs}

NHM envisaged that all ASHAs should be trained in the treatment of minor ailments such as fever, pain, diarrhea and first-aid for minor injuries at the earliest to help the community serve better and promptly. For the purpose, a basic medicine kit needs to be made available to them. With regard to drug kit received from the state health department, 17 of the total of 18 ASHAs (94.4 per cent) nodded in positive on the query whether they have received any drug kit from state government or not.

On further being asked about the type of medicines they received during the last year preceding the survey, the ASHAs did not portray a happy situation on the count of availability of medicines with them. The NHM had envisaged that AYUSH medications shall be included in the drug kit provided at village level to ASHAs. This practice was found completely absent. The situation on the count of availability of folic acid tablets, zinc tablets and emergency contraceptives was also dismal. About 60 per cent of the ASHAs stated that the supply of even paracetamol tablets/syrup is not satisfactory. There were delays in the replenishment of drugs and lack of timely replacement of drug kits to ASHAs.

Similar was the situation regarding availability of allopathic drugs in kits of ASHAs in Orissa. Even paracematol tablets were not given regularly to them. However their kits had AYUSH medicines but they lacked knowledge about using those medicines (NIHFW, NIAHRD and UNFPA, 2007-08).

\section{Monetary Compensation}

The state of Punjab was not giving any fixed honorarium on a monthly basis, unlike the neighbouring state of Haryana. All the ASHAs reported that their average monthly honorarium received through different incentives was less than Rs 900. The low compensation has made about 90 per cent of the ASHAs to feel dissatisfied. Poor monetary incentives affected the performance of ASHAs was reported by studies conducted in other states as well like rapid appraisal study conducted in Orissa (NIHFW, NIAHRD and UNFPA, 2007-08) and quality assessment study carried out in Maharashtra (Guha, I. et al. 2018).

Further ASHAs in Punjab stated that the monetary compensation they received isn't sufficient for the efforts that they are putting in. Their expectation is that the monthly honorarium should be around INR. 3,000. Irregularity in the incentives received was another factor which was making 
80 per cent of the ASHAs to feel dissatisfied. Potential for cuts and demands from ASHAs compensation was reported to be one factor demotivating them to perform their assigned tasks to the best of their abilities. It was reported that a specific amount has been fixed by these staff members for getting their due clear in time. Those who paid the fixed amount got their incentives cleared on time while those who refused this money were made to make repeated visits. This has led to a net loss to ASHA programme in the state.

\section{Awareness Level}

All the ASHAs were aware of the importance of bringing changes in the food intake of pregnant woman (Table 3). All had advised pregnant women to take vitamin and iron supplements during the pregnancy in addition to increasing the diet. Their awareness on the importance of giving neat and clean bed sheet and hygienic room at the time of home delivery was found lacking among about 60 per cent of them.

All ASHAs were aware of the importance of giving colostrums to the newborn as well as on the importance of wrapping newborn baby immediately after the birth especially in the winters. None of the ASHAs felt that evil spirits influence the birth of the child.

Almost all ASHAs had the wrong impression that a sick child should not be immunized on the immunization day. However, awareness level among ASHAs on the diarrhea management was quite high. Besides taking other precautions and providing recommended treatment all ASHAs opined that a child should continue to be breastfed in case of diarrhea. Interestingly, two of the 18 ASHAs (11 per cent) felt that a condom can be used more than once. About 17 per cent of the ASHAs were not aware of the duration within which emergency contraceptive pill should be taken in case of unprotected sex. Further, 61 per cent of the ASHAs did not have correct awareness on the importance of using condom for three months after vasectomy. The majority of the ASHAs were not aware on all the causative agents of AIDS. Half of them had the wrong belief that mosquito bites could be the one cause for HIV transmission. Another wrong belief among 20 per cent of ASHAs was that HIV can be transmitted through sharing of food and clothes.

\section{Support Mechanism of ASHAs}

That ASHAs must regularly interact with ANMs, PRI members and anganwadi workers is encapsulated in the activities assigned to them under the NHM. This could become the basis of their work planning, community based monitoring and supervision.
Table 3: Awareness level of ASHA on different aspects $(\mathrm{N}=18)$

\begin{tabular}{|c|c|}
\hline Parameters of awareness & $\begin{array}{l}\text { Number of } \\
\text { ASHAs } \\
\text { (in per cent) }\end{array}$ \\
\hline $\begin{array}{l}\text { Aware of danger signs that may occur during } \\
\text { pregnancy }\end{array}$ & $18(100.0)$ \\
\hline Diet to be increased during pregnancy & $18(100.0)$ \\
\hline $\begin{array}{l}\text { Vitamin and iron supplements during the } \\
\text { pregnancy }\end{array}$ & $18(100.0)$ \\
\hline \multicolumn{2}{|c|}{ Awareness on the precaution to be taken during home delivery } \\
\hline Hygienic room & $8(44.4)$ \\
\hline Neat and clean bed sheet & $7(38.9)$ \\
\hline New blade & $18(100.0)$ \\
\hline Thread & $16(88.9)$ \\
\hline Soap & $13(72.2)$ \\
\hline Gloves & $1(5.6)$ \\
\hline Colostrums should be given to newborn & $18(100.0)$ \\
\hline $\begin{array}{l}\text { Newborn should be wrapped immediately after } \\
\text { birth especially in winters }\end{array}$ & $18(100.0)$ \\
\hline Age at which the child should get supplements & $18(100.0)$ \\
\hline \multicolumn{2}{|c|}{ ASHAs opinion about child immunization in case of high fever } \\
\hline No postponement of immunization & $1(5.6)$ \\
\hline Postpone immunization & $17(94.4)$ \\
\hline $\begin{array}{l}\text { A child should continue to be breastfed in case } \\
\text { of diarrhea }\end{array}$ & $18(100.0)$ \\
\hline \multicolumn{2}{|c|}{$\begin{array}{l}\text { Awareness on taking emergency contraceptive pill after } \\
\text { unprotected sex }\end{array}$} \\
\hline Within 72 hours of unprotected sex & $12(66.7)$ \\
\hline 24 hours & $1(5.6)$ \\
\hline 48 hours & $2(11.1)$ \\
\hline Don't know & $3(16.7)$ \\
\hline \multicolumn{2}{|l|}{$\begin{array}{l}\text { Awareness on use of condom after undergoing } \\
\text { vasectomy }\end{array}$} \\
\hline $\begin{array}{l}\text { Condom to be used for three months after } \\
\text { vasectomy }\end{array}$ & $7(38.9)$ \\
\hline $\begin{array}{l}\text { Condom need not to be used for three months } \\
\text { after vasectomy }\end{array}$ & $8(44.4)$ \\
\hline Don't know & $3(16.7)$ \\
\hline \multicolumn{2}{|l|}{ Awareness on mode of HIV/AIDS transmission } \\
\hline Touching & $1(5.6)$ \\
\hline Contaminated blood transfusion & $17(94.4)$ \\
\hline Contaminated needles & $18(100.0)$ \\
\hline From infected mother to child & $18(100.0)$ \\
\hline Unprotected sex with infected partner & $18(100.0)$ \\
\hline Mosquito bite & $9(50.0)$ \\
\hline Sharing food and clothes & $3(16.7)$ \\
\hline
\end{tabular}




\subsection{Auxiliary Nurse Midwives}

It was found that 16.7 per cent of ANMs and ASHAs met daily, the other 77.8 per cent met once in a week and the remaining 5.5 per cent met once in a fortnight. During the cluster meetings about 80 per cent of the ANMs reported that they shared problems with ASHAs. One-third of the ANMs stated that ASHA workers met the PRI members at least once a week and 50 per cent met once in a fortnight. The purpose of these meetings was primarily to take stock of cleanliness and sanitation programme in the village and to assess monetary requirements.

Nonetheless, the conflict between ANMs and ASHAs was quite evident during discussion with them, but it did not have any negative bearing on their coordination. The point of disagreement was regarding overlapping of ASHAs and ANMs roles.

In a study conducted in Jharkhand, one-half of the ANMs met ASHAs more than five times in a month and 66.7 per cent were fully satisfied with their services (Karir S et al., 2015).

\section{Panchayati Raj Institutions}

All the PRI members knew ASHAs in their village and were interacting with them. A little more than 60 per cent of the PRI members stated that they themselves were directly involved in the selection of the ASHAs. The PRI members also felt that spirit of volunteerism among ASHAs was absent.

According to PRI members the services related to immunization of women and children, institutional deliveries and cleanliness in the village have improved significantly because of the intervention made by ASHAs while ASHAs have not been able to make a dent on motivating the community to construct latrine facilities and drug de-addiction. All the members of the PRIs opined that ASHA programme should be continued in their village. In some cases, the PRI members felt that the village population was quite scattered, making it difficult for ASHA to provide all kinds of services on a regular basis. In such cases, ASHAs should be given some facility for increasing their mobility may be a cycle to cover the whole population in such villages.

\section{Anganwadi Workers}

ASHAs must regularly interact with AWWs to mobilize the community so as to increase the outreach of health services. All AWWs were interacting with ASHAs regularly with a frequency of at least once a week, especially on the immunization day. The interaction between the AWWs and ASHAs was primarily in connection with the activities related to immunization, birth and death registration, distribution of IFA tablet/syrup, worm tablet distribution, management of malnourished children, on Mamta Divas and weighing of the newborn. However, it was observed that the AWWs were not very clear on their roles via-a-vis ASHA workers. As per the views expressed by AWWs, the spirit of volunteerism was absent among ASHAs. Most of the AWWs felt that ASHAs have not been able to make a dent on health awareness among the adolescents, improving the hygiene amongst the villagers and on drug de-addiction. All of them recommended continuation of the ASHA worker programme.

A study of Karir $S$ et. al. conducted in Jharkhand in 2015 gave that 68.7 per cent of AWWs met ASHA more than five times a month and 75 per cent of the AWWs were satisfied with her services.

\section{Eligible Women}

Eligible women are the direct beneficiaries of ASHA scheme. It has emerged from field survey that all the sampled eligible women have heard of ASHA and 97.8 per cent reported that ASHAs had visited their household as per the requirement of the households. One-third of the eligible women reported that ASHA has visited their household during the last one week prior to the survey and 51 per cent during the last one month prior to the survey.

About 90 per cent of the eligible women affirmed to have received support services from ASHAs on activities related to immunization of newborn, antenatal care service, advice on institutional deliveries and advice on breastfeeding practices (Table 4). ASHAs support in case of early registration of pregnancy, postnatal care services and family planning services was recognized by 70 per cent of the eligible women. Only three per cent of the eligible women reported that they did not get any service from the ASHAs of their respective villages.

ASHAs advice on danger signs of Acute Respiratory Infection (ARI) among children was dismal. Less than 20 per cent of the eligible women asserted to have received advice on danger signs of ARI. Almost all eligible women interviewed during the survey opined that ASHAs are available to all the community members irrespective of caste or economic status. They were not biased towards any particular community. Majority of the eligible women had a strong feeling that ASHAs presence in the village has proved beneficial to augment health status of villagers. None of the eligible women reported to have paid back to ASHAs in lieu of services provided by them. That is the reason why 98 per cent of the eligible women agreed that the ASHA programme should be continued; 32 per cent strongly agreed and 66 per cent agreed in this regard. 
Table 4: Support services received by the eligible women from ASHAs $(\mathrm{N}=90)$

\begin{tabular}{|l|l|}
\hline $\begin{array}{l}\text { Services provided by ASHA during last } \\
\text { pregnancy }\end{array}$ & $\begin{array}{l}\text { Number of } \\
\text { women } \\
\text { (in per cent) }\end{array}$ \\
\hline Immunization of newborn & $84(93.3)$ \\
\hline Antenatal care services & $80(88.9)$ \\
\hline Advice on institutional delivery & $80(88.9)$ \\
\hline Breastfeeding practices & $80(88.9)$ \\
\hline Early registration of pregnancy & $69(76.7)$ \\
\hline Post natal care services & $61(67.8)$ \\
\hline Family planning & $60(66.7)$ \\
\hline Natal care services & $57(63.3)$ \\
\hline Accompany women for institutional delivery & $48(53.3)$ \\
\hline JSY incentives & $41(45.6)$ \\
\hline Management of complications during delivery & $40(44.4)$ \\
\hline Providing medicines & $21(23.3)$ \\
\hline Importance of managing hygiene & $21(23.3)$ \\
\hline Arrangement of transport facilities & $14(15.6)$ \\
\hline DOTS & $6(6.7)$ \\
\hline None & $3(3.3)$ \\
\hline
\end{tabular}

\section{Conclusions}

The norms, including the age limit, educational qualification, residence and marital status set for the selection of ASHAs revealed clear adherence of the NHM guidelines in Punjab. The views of ANMs, PRI members and AWWs further substantiate that the selection process was smooth and candidates were selected on their merit without any biases. Literacy level, good rapport with the villagers, interest in performing health related tasks and past experience in managing health activities were the parameters considered to be important for selecting ASHAs by the Gram Sabhas.

The expected philosophy of ASHA as a volunteer was not a decisive factor motivating them to join as an ASHA worker. Those activities which were associated with financial enticement got higher priority while additional activities were largely ignored by them. Potential for cuts and demands from ASHAs compensation was one factor demoralizing them to perform their assigned tasks to the best of their abilities.

Inter-sectoral collaboration among the ASHAs, ANMs, PRI members and AWWs was more or less satisfactory even though ASHAs intervention in VHSNC meeting was not encouraging due to non-cooperation of other stakeholders and the leakage of money by the PRIs for the tasks which were beyond the purview of these Committees.

On the whole, ASHAs have been widely accepted by the village community as an important stakeholder in the promotion of health services. As envisaged under NHM, they have proved to be an important link between the targeted groups and the public health outlets. For strengthening the ASHA worker programme, a strong mechanism needs to put in place as regards checking the leakage of the money sanctioned to VHSNC. This would give them confidence to perform their activities with greater zeal leading to the success of the ASHA programme in the state of Punjab.

\section{References}

CORT (2007). Assessment of ASHA and Janani Suraksha Yojana in Rajasthan. Sponsored by UNFPA, New Delhi, 1-79.

http://nrhm.gov.in/communitisation/asha/resources/ asha-training-modules.html accessed at different point of time.

Ishita, Guha., Raut, V, Abhishek., Maliye, H, Chetna., Mehendale, M, Ashok., \& Garg, S, Bishan. (2018). Qualitative Assessment of Accredited Social Health Activists (ASHA) Regarding Their Roles and Responsibilities and Factors Influencing Their Performance in Selected Villages of Wardha. International Journal of Advanced Medical and Health Research, 5(1), 21-26.

https://doi.org/10.4103/IJAMR.IJAMR_55_17

National Institute of Health \& Family Welfare, National Institute of Applied Human Research and Development and UNFPA (2007-08). A Rapid Appraisal of Functioning of ASHA under NRHM in Cuttack, Orissa, 1-37.

National Institute of Health \& Family Welfare, State Institute of Health and Family Welfare and UNFPA (2008). Assessment of the Functioning of ASHAs under NRHM in Uttar Pradesh (2007-08), 1-27.

Sangeeta, Kori., Bhatia, Manohar., \& Mishra, Ashok. (2015). A Cross-sectional Assessment of Knowledge of ASHA Workers. Journal of Krishna Institute of Medical Science University, 4(4), 57-63.

Shilpa, Karir., Haider, Shamim., Kashyap, Vivek., Sagar, Vidya., \& Singh, Bhushan, Shashi. (2015). Assessment of Sahiyya (Accredited Social Health Activist) in relation to antenatal services: Ormanjhi, Ranchi, Jharkhand. International Journal of Community Medicine and Public Health, 2(2), 130-136. https://doi.org/10.5455/2394-6040.ijcmph20150513

Srinivas, Nagaraj., Achapppa, Santosh., Bettapa, Prashantha., \& B, Prakash. (2017). Performance Evaluation of Accredited Social Health Activist under National Rural Health Mission in Mysore District: A Cross-Sectional Study. National Journal of Community Medicine, 8(6), 324-328. 